\title{
Editorial: Astrobiology at the Interface: Interactions Between Biospheres, Geospheres, Hydrospheres and Atmospheres Under Planetary Conditions
}

\author{
Tetyana Milojevic ${ }^{1 *}$, Adrienne Kish $^{2}$ and Akihiko Yamagishi ${ }^{3}$ \\ ${ }^{1}$ Space Biochemistry Group, Department of Biophysical Chemistry, University of Vienna, Vienna, Austria, ${ }^{2}$ Muséum National \\ d'Histoire Naturelle, Paris, France, ${ }^{3}$ Department of Applied Life Sciences, School of Life Sciences, Tokyo University of \\ Pharmacy and Life Sciences, Hachioji, Japan
}

Keywords: astrobiology, outer space, extremophiles, ISS, Universe, Mars, space simulating facilities, biosignatures

Editorial on the Research Topic

OPEN ACCESS

Edited by:

André Antunes,

Macau University of Science and

Technology, China

Reviewed by:

Michael Macey,

The Open University, United Kingdom

*Correspondence:

Tetyana Milojevic

tetyana.milojevic@univie.ac.at

Specialty section:

This article was submitted to

Extreme Microbiology,

a section of the journal

Frontiers in Microbiology

Received: 16 November 2020

Accepted: 26 January 2021

Published: 12 February 2021

Citation:

Milojevic T, Kish A and Yamagishi A

(2021) Editorial: Astrobiology at the

Interface: Interactions Between

Biospheres, Geospheres,

Hydrospheres and Atmospheres Under Planetary Conditions.

Front. Microbiol. 12:629961.

doi: 10.3389/fmicb.2021.629961
Astrobiology at the Interface: Interactions Between Biospheres, Geospheres, Hydrospheres and Atmospheres Under Planetary Conditions

Astrobiology is a young, rapidly developing branch of science that seeks to address the question of whether life exists, or has existed, elsewhere in the Universe. It is by nature an interdisciplinary field that explores the origins of life, the conditions and processes that support or challenge life, the influence of different environmental conditions on the preservation and detection of biosignatures of past and present life, and the spread of life across the Universe.

As highly interdisciplinary field, astrobiology requires an integrative approach to link the efforts of microbiologists exploring the origins, evolution, and limits of life to the work of geologists exploring both planetary conditions (past and present) and preservation of biosignatures in the geological record. In the search for potential life on other planetary bodies, efforts are being made to combine exoplanet discovery, the study of asteroids and comets, ground-based analyses of recovered meteorites, microbial space exposure experiments with analog planetaryscale biosignature detection. Being a few steps in front of retrieving and returning the first samples from the surface of Mars, we have already gained extensive knowledge from the field, laboratory, and space exposure experiments (McKay and Stoker, 1989; Grotzinger and Milliken, 2012; Westall et al., 2015; Hays et al., 2017). This should enable a comprehensive characterization of the first Mars returned samples in terms of potential exobiology.

Outer space, along with ground-based simulating facilities, provides a research tool for studying life in the Universe. Multiple microbial exposure experiments have been successfully performed on board and outside of the International Space Station under the environmental conditions of low Earth orbit (Cockell et al., 2011; Nicholson et al., 2012; Vaishampayan et al., 2012; Kawaguchi et al., 2020; Ott et al., 2020) or mimicking planetary constraints (galactic cosmic and solar UV radiation, temperature fluctuations, microgravity, freezing, desiccation, and extreme vacuum) (Nicholson et al., 2012; Billi et al., 2019; de Vera et al., 2019; Panitz et al., 2019). Exposure experiments at ground-based simulating facilities have enabled the investigation of the effects of space-related parameters on microbial survival and adaptation capacities (Mastroleo et al., 2013; Ott et al., 2019a,b; Beblo-Vranesevic et al., 2020). 
Revealing unknown boundaries for prokaryotic life under multiple extremes is a prerequisite to understanding the extent of biology on Earth, and to discover its possible wider presence in the Universe. Understanding freezing tolerance and survival limits of thermophiles in permanently cold habitats is important for studies of microbial transfer through space and between celestial bodies. The peculiar presence of thermophiles in permanently cold marine and terrestrial habitats, including Arctic marine sediments (Hubert et al., 2009; Hanson et al., 2019), cold seawaters (Mora et al., 2014; Wirth, 2017), Antarctic accretion ice (Bulat et al., 2004; Lavire et al., 2006), permafrost (Gilichinsky et al., 2007; Demidov and Gilichinsky, 2009), and laboratory investigations of thermophiles under low temperatures (Marchant et al., 2008; Milojevic et al., 2020) has been known for many years. However, our understanding of the molecular and physiological mechanisms of thermophilic adaptation to low temperatures is still poor.

The papers in this Research Topic cover a range of microbiological and biochemical research in extreme environments, from cold marine sediments with permanent low temperatures to hot springs in Yellowstone National Park, and to drilling samples from millions-year-old oceanic crust with deep fractured rock ecosystems. These papers provide a snapshot of current research activities in the field of astrobiology that have evolved at the boundaries of biosphere, geosphere, hydrosphere and atmosphere. In this research collection we present one review and 8 original research papers exploring the interactions between the biological, geological, hydrological, and atmospheric elements in the Universe. These works seek to address the impact of planetary conditions on the evolution of microorganisms, molecular mechanisms driving the limits of life under different physiochemical regimes, and traces of life that can be detected in the physiochemical conditions of Earth and beyond.

Several papers in this collection are addressing the survival limits of extremophiles exposed to harsh space-related parameters and drastic planetary constraints. Mosca et al. studied the desert cyanobacterium Chroococcidiopsis exposed to a Mars-like UV flux and long-termed desiccation. Their study reshaped the boundaries of Chroococcidiopsis desiccation and UV tolerance and revealed several molecular determinants of DNA damage and repair response of Chroococcidiopsis.

A review by Milojevic and Weckwerth presents further detailed analysis of molecular mechanisms behind microbial survival and adaptation to an outer space environment. This review is focused on molecular strategies revealed with the help of the global and integrative -omics approaches of systems biology that have been recently used to study microorganisms exposed to real and simulated space conditions. Popall et al. investigated the influence of UV-C radiation on cultures dominated by the cyanobacterium Geitlerinema sp., which was obtained from a laboratory-maintained stromatolite originating from a Precambrian analog lagoonal system Lagoa Vermelha, Brazil. The Geitlerinema sp. was able to withstand long-term exposure to $\mathrm{UV}-\mathrm{C}$ radiation, building and maintaining filamentous mats after harmful irradiation.
The other papers in this Research Topic issue illustrate co-evolution of biosphere, geosphere, and hydrosphere, and consider biosignatures of life formed at their interfaces. Boyer et al. analyzed the influence of redox geochemistry on lipid composition of microbial communities inhabiting hot springs in Yellowstone National Park. This study proposed chemical signatures in lipid biomarkers that could potentially represent a fingerprint of the geochemical paleoredox conditions on microorganisms inhabiting these paleoenvironments. Sueoka et al. investigated a basaltic rock core sample of 104-millionyear-old oceanic crust and proposed that deep saponite-bearing fractures could harbor extant life and/or host the remnants of bygone life on Mars. Hamilton-Brehm et al. described a novel anaerobic and thermophilic bacterium Thermoanaerosceptrum fracticalcis isolated from deep fractured rock ecosystems of the US Great Basin and provided insights into metabolic strategies of the deep subsurface biosphere. Glamoclija et al. studied subsurface microbial ecology of hypersaline playa Lake Lucero at the White Sands National Monument in New Mexico and proposed this region as a terrestrial analog for future astrobiological explorations. The limits of microbial life in saline and cold environments with potential implications for habitability of Martian cryobrines were a focus of investigations by Waajen et al. Their laboratory investigations showed that salt concentration, anion parameters and the water activity are crucial factors in the survival of the cryo- and halotolerant bacterial strain Planococcus halocryophilus in concentrated brines. Thus, anion brine composition, the salt concentration and water activity were proposed as a set of environmental parameters to be considered when investigating potential habitability of Martian cryobrines. Microbial life under extremely low temperatures was also investigated by Cramm et al., who studied the influence of freezing temperatures on the survival of thermophilic endospore-forming bacteria. Their laboratory study showed that thermospores remain viable after freezing at temperatures as low as $-80^{\circ} \mathrm{C}$, making them suitable for microbial viability investigations in Martian surface soil with temperature fluctuations between 20 and $-76^{\circ} \mathrm{C}$.

In summary, this Research Topic includes both novel research strategies and methodologies that should yield promising results in the future, expanding our current view of life-search across the Universe.

\section{AUTHOR CONTRIBUTIONS}

The authors are co-editors which organized this Research Topic, substantially, directly, and intellectually contributed to the work on this Research Topic and the manuscript, and approved it for publication. All authors contributed to the article and approved the submitted version.

\section{ACKNOWLEDGMENTS}

We warmly thank all contributing authors for submission of their papers to the Research Topic. The authors gratefully acknowledge the reviewers for their time spent on the manuscripts and valuable suggestions. 


\section{REFERENCES}

Beblo-Vranesevic, K., Bohmeier, M., Schleumer, S., Rabbow, E., Perras, A. K., Moissl-Eichinger, C., et al. (2020). Impact of simulated martian conditions on (facultatively) anaerobic bacterial strains from different Mars analogue sites. Curr. Issues Mol. Biol. 38, 103-122. doi: 10.21775/cimb.038.103

Billi, D., Staibano, C., Verseux, C., Fagliarone, C., Mosca, C., Baqu,é, M., et al. (2019). Dried biofilms of desert strains of chroococcidiopsis survived prolonged exposure to space and Mars-like conditions in low Earth orbit. Astrobiology 19, 1008-1017. doi: 10.1089/ast.2018.1900

Bulat, S. A., Alekhina, I. A., Blot, M., Petit, J. R., Angelis, M., Waggenbach, D., et al. (2004). DNA signature of thermophilic bacteria from the aged accretion ice of Lake Vostok, Antarctica: implications for searching for life in extreme icy environments. Int. J. Astrobiol. 3, 1-12. doi: 10.1017/S1473550404001879

Cockell, C. S., Rettberg, P., Rabbow, E., and Olsson-Francis, K. (2011). Exposure of phototrophs to 548 days in low Earth orbit: microbial selection pressures in outer space and on early earth. ISME J. 5, 1671-1682. doi: 10.1038/ismej.2011.46

de Vera, J.-P. P., Alawi, M., Backhaus, T., Baqu,é, M., Billi, D., Böttger, U., et al. (2019). Limits of life and the habitability of Mars: the ESA space experiment BIOMEX on the ISS. Astrobiology 19, 145-157. doi: 10.1089/ast.2018.1897

Demidov, N. E., and Gilichinsky, D. A. (2009). "Terrestrial permafrost models and analogues of martian habitats and inhabitants," in Permafrost Soils, ed R. Margesin (Berlin: Springer), 334.

Gilichinsky, D. A., Wilson, G. S., Friedmann, E. I., McKay, C. P., Sletten, R. S., Rivkina, E. M., et al. (2007). Microbial populations in Antarctic permafrost: biodiversity, state, age, and implication for astrobiology. Astrobiology 7, 275-311. doi: 10.1089/ast.2006.0012

Grotzinger, J. P., and Milliken, R. E. (2012). "The sedimentary rock record of Mars: Distribution, origins, and global stratigraphy," in Sedimentary Geology of Mars, SEPM, eds J. P. Grotzinger and R. E. Milliken (Tulsa, OK: Society for Sedimentary Geology).

Hanson, C. A., Müller, A. L., Loy, A., Dona, C., Appel, R., Jørgensen, B. B., et al. (2019). Historical factors associated with past environments influence the biogeography of thermophilic endospores in Arctic marine sediments. Front. Microbiol. 10:245. doi: 10.3389/fmicb.2019.00245

Hays, L. E., Graham, H. V., Des Marais, D. J., Hausrathm, E. M., Horgan, B., McCollom, T. M., et al. (2017). Biosignature preservation and detection in mars analog environments. Astrobiology 4, 363-400. doi: 10.1089/ast.2016.1627

Hubert, C., Loy, A., Nickel, M., Arnosti, C., Baranyi, C., Brüchert, V., et al. (2009). A constant flux of diverse thermophilic bacteria into the cold Arctic seabed. Science 325, 1541-1544. doi: 10.1126/science.1174012

Kawaguchi, Y., Shibuya, M., Kinoshita, I., Yatabe, J., Narumi, I., Shibata, H., et al. (2020). DNA damage and survival time course of deinococcal cell pellets during 3 years of exposure to outer space. Front. Microbiol. 11:2050. doi: $10.3389 /$ fmicb.2020.02050

Lavire, C., Normand, P., Alekhina, I., Bulat, S., Prieur, D., Birrien, J. L., et al. (2006). Presence of Hydrogenophilus thermoluteolus DNA in accretion ice in the subglacial Lake Vostok, Antarctica, assessed using rrs, cbb and hox. Environ. Microbiol. 8, 2106-2114. doi: 10.1111/j.1462-2920.2006.01087.x

Marchant, R., Franzetti, A., Pavlostathis, S. G., Tas, D. O., Erdbrugger, I., Unyayar, A., et al. (2008). Thermophilic bacteria in cool temperate soils: are they metabolically active or continually added by global atmospheric transport? Appl. Microbiol. Biotechnol. 78, 841-852. doi: 10.1007/s00253-008-1372-y
Mastroleo, F., Van Houdt, R., Atkinson, S., Mergeay, M., Hendrickx, L., Wattiez, R., et al. (2013). Modelled microgravity cultivation modulates $\mathrm{N}$-acylhomoserine lactone production in Rhodospirillum rubrum S1H independently of cell density. Microbiology 159, 2456-2466. doi: 10.1099/mic.0.066415-0

McKay, C. P., and Stoker, C. R. (1989). The early environment and its evolution on Mars: implication for life. Rev. Geephys. 2, 189-214.

Milojevic, T., Zebec, Z., and Schimak, M. P. (2020). Cultivation with powdered meteorite (NWA 1172) as the substrate enhances low-temperature preservation of the extreme thermoacidophile Metallosphaera sedula. Front. Astron. Space Sci. 7:37. doi: 10.3389/fspas.2020.00037

Mora, M., Bellack, A., Ugele, M., Hopf, M., and Wirth, R. (2014). The temperature gradient forming device: an accessory unit for normal light microscopes to study the biology of hyperthermophilic microorganisms. Appl. Environ. Microbiol. 80, 4764-4770. doi: 10.1128/AEM.00984-14

Nicholson, W. L., Moeller, R., PROTECT Team and Horneck, G. (2012). Transcriptomic responses of germinating Bacillus subtilis spores exposed to 1.5 years of space and simulated martian conditions on the EXPOSE-E experiment PROTECT. Astrobiology 12, 469-486. doi: 10.1089/ast.2011.0748

Ott, E., Fuchs, F., Moeller, R., Hemmersbach, R., Kawaguchi, Y., Yamagishi, A., et al. (2019a). Molecular response of Deinococcus radiodurans to simulated microgravity explored by proteometabolomic approach. Sci. Rep. 9:18462. doi: 10.1038/s41598-019-54742-6

Ott, E., Kawaguchi, Y., Kölbl, D., Rabbow, E., Rettberg, P., Mora, M., et al. (2020). Molecular repertoire of Deinococcus radiodurans after 1 year of exposure outside the International Space Station within the Tanpopo mission. Microbiome 8:150. doi: 10.1186/s40168-020-00927-5

Ott, E., Kawaguchi, Y., Özgen, N., Yamagishi, A., Rabbow, E., Rettberg, P., et al. (2019b). Proteomic and metabolomic profiling of Deinococcus radiodurans recovering after exposure to simulated low earth orbit vacuum conditions. Front. Microbiol. 10:909. doi: 10.3389/fmicb.2019.00909

Panitz, C., Frösler, J., Wingender, J., Flemming, H. C., and Rettberg, P. (2019). Tolerances of Deinococcus geothermalis biofilms and planktonic cells exposed to space and simulated Martian conditions in low Earth orbit for almost two years. Astrobiology 19, 979-994. doi: 10.1089/ast.2018.1913

Vaishampayan, P. A., Rabbow, E., Horneck, G., and Venkateswaran, K. J. (2012). Survival of Bacillus pumilus spores for a prolonged period of time in real space conditions. Astrobiology 12, 487-497. doi: 10.1089/ast.2011.0738

Westall, F., Foucher, F., Bost, N., Bertrand, M., Loizeau, D., Vago, J. L., et al. (2015). Biosignatures on Mars: what, where, and how? Implications for the search for Martian life. Astrobiology 11, 998-1029. doi: 10.1089/ast.2015.1374

Wirth, R. (2017). Colonization of black smokers by hyperthermophilic microorganisms. Trends Microbiol. 2, 92-99. doi: 10.1016/j.tim.2016.11.002

Conflict of Interest: The authors declare that the research was conducted in the absence of any commercial or financial relationships that could be construed as a potential conflict of interest.

Copyright (c) 2021 Milojevic, Kish and Yamagishi. This is an open-access article distributed under the terms of the Creative Commons Attribution License (CC BY). The use, distribution or reproduction in other forums is permitted, provided the original author(s) and the copyright owner(s) are credited and that the original publication in this journal is cited, in accordance with accepted academic practice. No use, distribution or reproduction is permitted which does not comply with these terms. 